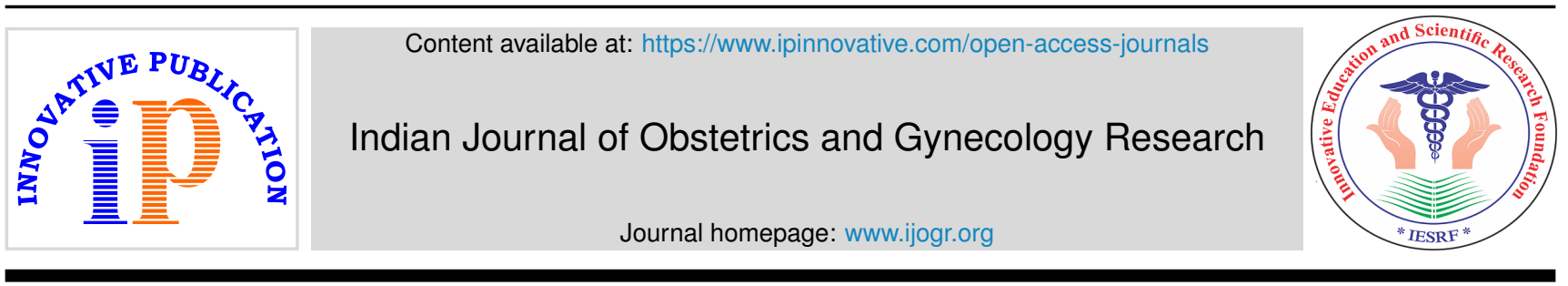

Original Research Article

\title{
Colloseum to estimate the accuracy of detection of cervical intraepithelial neoplasia using electrical impedance spectroscopy with colposcopy- A one year study
}

\author{
Shalini Vasudeva ${ }^{1}$, Ragini Thapa ${ }^{2, *}$ \\ ${ }^{1}$ Dept. of Gynecology and Obstetrics, Military Hospital Mhow, Indore, Madhya Pradesh, India \\ ${ }^{2}$ Dept. of Pathology, Military Hospital Mhow, Indore, Madhya Pradesh, India
}

\section{A R T I C L E I N F O}

\section{Article history:}

Received 11-01-2021

Accepted 12-02-2021

Available online 11-06-2021

\section{Keywords:}

CIN

Electrical impedance spectroscopy

ZedScan

\begin{abstract}
A B S T R A C T
Background: Cervical cancer is ranked as the second most common cancer amongst women worldwide and in many low-income countries, it is the most common female cancer. ZedScan, enables us to have a first hand estimation of the accuracy of the system and thereby settling and verifying the claims of the manufacturer.

Aim: To prove, easy detection of cervical carcinoma by using EIS as an adjunct to colposcopy giving better detection rates in (CIN)cervical intraepithelial neoplasm with increased diagnostic accuracy.

Materials and Methods: It was a prospective study done on a sample size of 200 patients. The patients were selected from amongst all the patients attending the Department of Obstetrics \& Gynaecology, Base Hospital, Delhi Cantt, either with a clinical indication or an abnormal cervical cytology. All such cases were recruited into the study with histopathology as a gold standard.

Results: Age of patients ranged from 30 to 68 years. Majority of women were aged between 31-40 years $(n=135 ; 67.5 \%)$. Mean age of patients was $37.48 \pm 6.3$ years. Almost all $(98.5 \%)$ the test patients were married. There were $3(1.5 \%)$ widowed/divorced women. Majority of women were educated up to graduation or above $(51 \%)$ followed by those educated upto 8 th standard $(\mathrm{n}=53 ; 26.5 \%)$ and those educated upto secondary level (22.5\%). BMI of women ranged from 20.11 to $32.30 \mathrm{~kg} / \mathrm{m} 2$. Majority were in overweight category $(\mathrm{n}=113 ; 56.5 \%)$. A total of $72(36 \%)$ had normal weight and $15(7.5 \%)$ were obese. Socioeconomically, 88 (44\%) belonged to upper middle, 74 (37\%) lower middle, 35 (17.5\%) to lower and $3(1.5 \%)$ to upper socioeconomic class. Histopathologically, a total of 26 cases were positive and 174 were negative. As compared to histopathology, ZedScan had 11 true positive, 5 false positive, 15 false negative and 169 true negative cases. Correspondingly, the sensitivity, specificity, positive predictive value, negative predictive value and accuracy value of ZedScan for any grade of neoplasia was $42.3 \%, 97.1 \%, 68.8 \%$, $90.9 \%$ and $90 \%$ respectively.

Conclusion: The findings of the study conducted thus suggest that ZedScan has a useful role as an adjunct to Colposcopy in the detection of cervical neoplasia, particularly that of high-grade CINs.

(C) This is an open access article distributed under the terms of the Creative Commons Attribution License (https://creativecommons.org/licenses/by/4.0/) which permits unrestricted use, distribution, and reproduction in any medium, provided the original author and source are credited.
\end{abstract}

\section{Introduction}

At the turn of the millennium, cervical cancer ranked as one of the most common cancer amongst women worldwide. Its prevalence is much more in developing countries where it is the most common rampant female cancer. ${ }^{1}$ Mortality due to

\footnotetext{
* Corresponding author.

E-mail address: ragpiyu2010@gmail.com (R. Thapa).
}

cervical cancer is also an indicator of health inequities, as $86 \%$ of all deaths ${ }^{2}$ due to cervical cancer are in developing, low- and middle-income countries. ${ }^{3}$

It is possible to prevent mortality due to cervical cancer through various strategies that target women $>30$ yr of age for screening and treatment. ${ }^{4}$ The introduction of Papanicolaou test heralded a significant reduction in 
mortality and morbidity in developed countries, the proportion of women being screened by Pap test vary from 68 to 84 per cent. ${ }^{5-7}$ Despite the existence of national guidelines the screening coverage in India is appalling and is mainly attributed to inequality between infrastructure, resources and outsized population. ${ }^{8}$ As a consequence, often the diagnosis of cervical cancer is based on opportunistic screening or after the onset of symptoms. The clinical screening programmes generally involve Pap smear evaluation and/or screening clinically through colposcopy. However, the clinical performance of colposcopy is subjective and variable, dependent on factors including disease prevalence and training. ${ }^{9,10}$ Also, the apparent success of the Pap smear in detecting preinvasive cancer, the expected beneficial impact vis-à-vis mortality reduction has not been significant. ${ }^{3}$ This situation shows that there is a dire need to increase the accuracy of diagnostic methods for successful detection of cases of cervical carcinoma.

Recently, Zilico has developed a device (the ZedScan) ${ }^{8}$ that uses cervical electrical impedance spectroscopy (EIS) during colposcopy to help locate cancer or pre-cancerous lesions. The device is claimed to enable clinicians to improve the diagnostic accuracy of colposcopy, meaning effective medical decisions with a need for fewer biopsies and a reduction in over-treatment of mild abnormalities.

EIS works on the principle that all tissues have an electrical impedance. This impedance varies depending on the type of tissue and its components. At high frequencies, more than $1 \mathrm{ghz}$ current enters the cell membrane. The nuclear size and cell volume determine the impedance to the flow of the current. ${ }^{8}$

Hence, the present study was planned to evaluate and assess the accuracy of the detection of cervical intraepithelial neoplasia using electrical impedance spectroscopy with colposcopy.

\section{Materials and Methods}

This was a prospective, comparative clinical study. The patients were selected from amongst all the patients attending the Department of Obstetrics \& Gynaecology, of a 600 bedded tertiary hospital clinic. Sample Size of 200 was selected for the study. Patients aged 25-65 years presenting with the clinical indication or abnormal cytology included in the study. Pregnant women and women actively menstruating at the time of examination were excluded from the study. Ethical approval was taken from the Institutional Ethics Committee. Informed consent was obtained from all the participants before inclusion.

\subsection{Tools \& Techniques}

Electrical impedance spectroscopy was carried out by specialised diagnostic system. It consists of a portable handheld device which has a pencil shaped probe on which a single-use EIS sensor is mounted. This sensor incorporates four gold electrodes which record impedance spectra from 12 points on the cervix. Spectra were also recorded from tissue boundaries. Colposcopic examinations, including probe positioning, were recorded to allow for correlations between histopathological diagnosis of colposcopically directed biopsies, colposcopic impression and the diagnosis based on impedance measurements. Impedance measurements using a $5.5 \mathrm{~mm}$ diameter pencil probe with four $0.6 \mathrm{~mm}$ diameter gold electrodes mounted flush with the face of the probe and a current of $<20$ $\mu \mathrm{A}$ p-p passed between an adjacent pair of electrodes and the resulting potential measured between the two remaining electrodes. Measurements were taken at 16 frequencies by doubling the frequency in steps from $76.3 \mathrm{~Hz}$ to $625 \mathrm{kHz}$. The probe was used to take a total of 12 measurements from the cervix Impedance measurements were automatically transferred to software on a laptop. Colposcopy was then performed, and cervical biopsies were taken wherever clinically indicated. The entire procedure from visualisation of the cervix followed by probe positioning, and summed up by haemostasis at the site of cervical biopsies, was recorded for subsequent correlation between results obtained from colposcopic impression, and the histopathological diagnosis of colposcopically directed biopsies and impedance. Colposcopic scoring was done using Modified Reid's colposcopic Index. ${ }^{11}$ Histopathology was taken as the gold standard.

Data were analysed using statistical package for social sciences (SPSS) version 21. Sensitivity, specificity, positive predictive, negative predictive and diagnostic accuracy of the techniques were calculated.

\section{Results}

Colposcopic scoring based on Reid's score were 0-2 indicative of normal/inflammatory findings in $85 \%, 3-4$ indicative of CIN I/II in 5.5\% and 5-8 indicative of CIN II/III in $9.5 \%$ cases.

ZedScan was positive in $16(8 \%)$ cases - thus suggestive of high grade/malignant lesions. It was negative in 184 $(92 \%)$ cases, suggesting normal/low grade lesions.

Biopsy findings were suggestive of negative status in $174(87 \%)$ and positive in $26(13 \%)$ cases. Among positive cases were CIN I (n=7), CIN II (n=5), CIN III (n=9) and SCC $(n=5)$ respectively. Among 174 negative cases -113 were negative for the presence of any malignant cell, 34 were diagnosed to have inflammatory cells, and 27 showed focal karyocytes negative for malignant cells.scoring based on Reid's score were 0-2 indicative of normal/inflammatory findings in $85 \%, 3-4$ indicative of CIN I/II in 5.5\% and 5-8 indicative of CIN II/III in $9.5 \%$ cases.

Table 4 shows the Sensitivity, Specificity, Positive predictive value and negative predictive value of various 
Table 1: Sociodemographic profile of patients $(\mathrm{N}=200)$

\begin{tabular}{|c|c|c|c|}
\hline S.No & Characteristic & No. & $\%$ \\
\hline \multirow{9}{*}{1.} & Age(yrs) & & \\
\hline & $<30$ & 19 & 9.5 \\
\hline & $31-35$ & 77 & 38.5 \\
\hline & $36-40$ & 58 & 29.0 \\
\hline & $41-45$ & 28 & 14.0 \\
\hline & $46-50$ & 13 & 6.5 \\
\hline & $51-55$ & 1 & 0.5 \\
\hline & $56-60$ & 2 & 1.0 \\
\hline & $>60$ & 2 & 1.0 \\
\hline \multirow{5}{*}{2.} & Mean Age \pm SD (Range) in years & \multicolumn{2}{|c|}{$37.48 \pm 6.3(30-68)$} \\
\hline & Marital Status & & \\
\hline & Married & 197 & 98.5 \\
\hline & Widowed/Divorced & 3 & 1.5 \\
\hline & Education & & \\
\hline \multirow{3}{*}{3.} & Upto Std VIII & 53 & 26.5 \\
\hline & Secondary Std XI-XII & 45 & 22.5 \\
\hline & Graduate and above & 102 & 51.0 \\
\hline \multirow{4}{*}{4.} & $\mathrm{BMI}\left(\mathrm{kg} / \mathrm{m}^{2}\right)$ & & \\
\hline & Normal weight (18.5-24.99) & 72 & 36.00 \\
\hline & Overweight (25.00-29.99) & 113 & 56.5 \\
\hline & Obese $(>30)$ & 15 & 7.5 \\
\hline
\end{tabular}

Table 2: Distribution of cases according to parity, menstrual status, contraception usage and age at marriage

\begin{tabular}{|c|c|c|c|}
\hline \multirow[t]{4}{*}{ S.No. } & Characteristic & No. & $\%$ \\
\hline & Parity & & \\
\hline & Para 0 & 17 & 8.5 \\
\hline & Para 1 & 27 & 13.5 \\
\hline \multirow[t]{5}{*}{1.} & Para 2 & 73 & 36.5 \\
\hline & Para 3 & 35 & 17.5 \\
\hline & Para 4 & 27 & 13.5 \\
\hline & $>$ Para 4 & 21 & 10.5 \\
\hline & Menopausal status & & \\
\hline \multirow{5}{*}{2.} & Pre & 185 & 92.5 \\
\hline & Peri & 9 & 4.5 \\
\hline & Post & 6 & 3.0 \\
\hline & Contraceptive History & 69 & 34.5 \\
\hline & Condom & 21 & 10.5 \\
\hline \multirow[t]{3}{*}{3.} & IUCD & 8 & 4.0 \\
\hline & Ligation & 4 & 2.0 \\
\hline & OCP & 36 & 18.0 \\
\hline \multirow[t]{7}{*}{4.} & Presenting Complaint & & \\
\hline & Abnormal bleeding & 193 & 96.5 \\
\hline & Foul smelling discharge & 53 & 26.5 \\
\hline & Frequent micturition & 111 & 55.5 \\
\hline & Pelvic pain & 98 & 49.0 \\
\hline & Painful urination & 97 & 48.5 \\
\hline & Age at menarche(years) & & \\
\hline \multirow[t]{3}{*}{5.} & $<12$ & 93 & 46.5 \\
\hline & $>12$ & 107 & 53.5 \\
\hline & Age at marriage (years) & & \\
\hline \multirow{3}{*}{6.} & $<20$ & 0 & 0 \\
\hline & $21-25$ & 92 & 46.0 \\
\hline & $>25$ & 108 & 54.0 \\
\hline
\end{tabular}


Table 3: Distribution of cases according to diagnostic workup

\begin{tabular}{llc}
\hline S.No. & Diagnostic Method & Percentage \\
1. & Colposcopically suspicious (CIN 1 and above) - subjected to biopsy examination & 15.0 \\
2. & Positive Colposcopically (CIN 2 and above) & 9.5 \\
3. & Positive ZedScan & 8.0 \\
4. & Positive Colpo+ZedScan & 14.5 \\
6. & Positive on histopathology & 7.0 \\
\hline
\end{tabular}

Table 4: Correlation betweencolposcopy, Zed-Scan, Colpo+EIS and histopathology

\begin{tabular}{|c|c|c|c|c|c|c|}
\hline & & Sensitivity & Specificity & PPV & NPV & Accuracy \\
\hline \multirow{2}{*}{$\begin{array}{l}\text { Between } \\
\text { Colposcopy and } \\
\text { Histopathology }\end{array}$} & $\begin{array}{l}\text { Any Positive (CIN any grade vs } \\
\text { Negative) }\end{array}$ & 69.2 & 93.1 & 60.0 & 95.3 & 90.0 \\
\hline & $\begin{array}{l}\text { Any Positive (High Grade (CIN } \\
\text { II/III or above) vs Negative) }\end{array}$ & 64.3 & 94.6 & 47.4 & 97.2 & 92.5 \\
\hline $\begin{array}{l}\text { Between } \\
\text { ZedScan and }\end{array}$ & $\begin{array}{l}\text { Any Positive (CIN any grade vs } \\
\text { Negative) }\end{array}$ & 42.3 & 97.1 & 68.8 & 90.9 & 90.0 \\
\hline Histopathology & $\begin{array}{l}\text { Any Positive (High Grade (CIN } \\
\text { II/III or above) vs Negative) }\end{array}$ & 64.3 & 96.2 & 56.3 & 97.3 & 94.0 \\
\hline \multirow{2}{*}{$\begin{array}{l}\text { Between } \\
\text { Colpo+EIS and } \\
\text { Histopathology }\end{array}$} & $\begin{array}{l}\text { Any Positive (CIN any grade vs } \\
\text { Negative) }\end{array}$ & 80.8 & 91.4 & 58.3 & 97.0 & 90.0 \\
\hline & $\begin{array}{l}\text { Any Positive (High Grade (CIN } \\
\text { II/III or above) vs Negative) }\end{array}$ & 85.7 & 90.9 & 41.4 & 98.8 & 90.5 \\
\hline
\end{tabular}

procedures with histopathology.

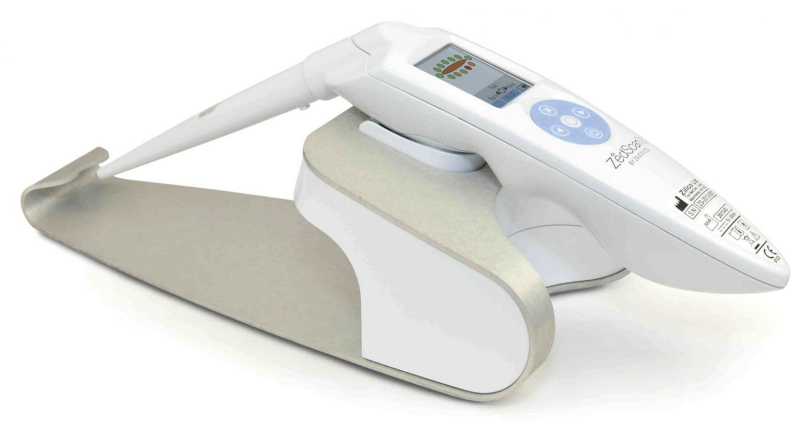

Fig. 1:

\section{Discussion}

In the present study, an attempt was made to evaluate the efficacy of electrical impedance probe as an adjunct to colposcopy in the diagnosis of high-grade Cervical Intraepithelial Neoplasia (CIN) in women referred with cervical smear abnormalities in day care opds.

200 women with a mean age of $37.48 \pm 6.3$ years were enrolled in the study. The age profile of women in different studies is ranged substantially. Compared to our study, Das et al. ${ }^{12}$ had conducted their study in a study population with a mean age of 54.6 years. However, Balasubramani et al. ${ }^{13}$ conducted their study in a relatively younger population like ours with an age of women ranging from 20 to 55 years. A more recent study by Macdonald et al. ${ }^{14}$ had included women in the age group of 20.3 to 66.1 years with a mean age of 32.9 years which is younger than that of cases enrolled in the present study. The difference in the age profile of cases included in various studies might influence the prevalence of cervical neoplasms in different study populations.

In the current study, almost all the women (98.5\%) were married, and a few $3(1.5 \%)$ were widowed/divorced. Most of the women were sexually active and were in premenopausal (92.5\%) stage of their life.

Younger age, healthy sexual activity and premenopausal stage are associated with a relatively lesser risk of cervical cancer. However, there is an increasing emerging consensus emerging regarding the usefulness of screening for cervical cancer even in younger and premenopausal women. ${ }^{9}$ In the present study too, we had included the women based on clinical features irrespective of age. The higher proportion of women in younger age group and even in premenopausal age group could be due to high level of awareness among our patients who were highly educated $(51 \%$ educated up to graduation or above) and a generally upper middle/upper class profile $(45.5 \%)$. Moreover, being in a service hospital where the emphasis is laid on complete diagnosis and cure, all the women, even with minimal suspicion were subjected to screening in order to rule out the minimal possibility of malignancy.

Majority of women enlisted in the study (53.5\%) had menarche at $>12$ years of age and were married at $>25$ years of age $(54 \%)$. Both early age at menarche and first sexual intercourse has been reported to be associated with an increased risk of cervical cancer; ${ }^{10}$ however, in the present study, no such risk was elaborated. 
In the present study it was observed that colposcopic scoring based on Reid's score were 0-2 indicative of normal/inflammatory findings in 85\%, 3-4 indicative of CIN I/II in $5.5 \%$ and 5-8 indicative of CIN II/III in $9.5 \%$ cases. The ZedScan findings were positive in $16(8 \%)$ cases - thus suggestive of high grade/malignant lesions. It was negative in $184(92 \%)$ cases, suggesting normal/low grade lesions. On the other hand, biopsy findings were suggestive of negative status in $174(87 \%)$ and positive in $26(13 \%)$ cases. Among positive cases were CIN I ( $n=7)$, CIN II ( $n=5)$, CIN III $(n=9)$ and SCC $(n=5)$ respectively. Among 174 negative cases - 113 were negative for the presence of any malignant cell, 34 were diagnosed to have inflammatory cells and 27 showed focal karyocytes negative for malignant cells.

Thus the prevalence of high-grade CIN III and SCC was $7 \%$ in the present study. Furthermore, the prevalence of cervical cancer was $2.5 \%$. Abdul et al. ${ }^{15}$ in their study reported high grade CIN in 178/1168 $(15.2 \%)$ EIS measurements. Balasubramani et al. ${ }^{13}$ in their study reported high grade CIN in 85/891 (9.5\%) EIS measurements in their study. Relatively lesser positivity rates in our study could be attributable to a high proportion of women with relatively lesser conventional risk factors of cervical cancer as elaborated earlier.

In present study for any abnormality (any CIN) detected during colposcopy and EIS independently had a sensitivity $\&$ specificity of $69.2 \% \& 93.1 \%$ and $42.3 \%$ \& $97.1 \%$ respectively. However, when EIS was used as an adjunct to colposcopy there as an appreciable increase in the sensitivity to $80.8 \%$ while maintaining the specificity at $91.4 \%$. For higher grade CIN too, colposcopy and EIS independently had a sensitivity \& specificity of $64.3 \% \& 94.6 \%$ and $64.3 \%$ $\& 96.2 \%$ respectively, which on the combination of two reached to $85.7 \%$ \& $90.9 \%$ respectively, thus demonstrating that for neoplasms in general and that of higher grades of neoplasms, the combined use of colposcopy with ZedScan helps to elevate the sensitivity and specificity substantially. Similar results were noted by, Abdul et al. (2006) ${ }^{15}$ on the evaluation of the MKIII version of the ZedScan. On performing a 'per woman' analysis to differentiate between any grade of CIN and a normal epithelium, his study found a sensitivity of $66.3 \%$ (69/104), a specificity of $49 \%$ $(27 / 55)$, the positive predictive value of $67.7 \%(69 / 96)$, and negative predictive value of $55 \%$ (35/63). The same analysis to identify CIN 2 and CIN 3 found a sensitivity of $74 \%$ (58/78), a specificity of $53 \%$ (42/80), the positive predictive value of $60 \%$, and negative predictive value of $67 \%(42 / 62)$. Balasubramanian (2009) ${ }^{13}$ also reported and evaluated a second-generation prototype version of the ZedScan. The study compared data obtained from cells before and after the application of acetic acid. It was reported that acetic acid application made no significant difference to the impedance spectra data. The 'per woman' analysis to detect highgrade CIN (CIN 2 and above) after acetic acid was applied found a sensitivity of $89.7 \%$ and a specificity of $50 \%$.
In a recent assessment too, Macdonald et al. ${ }^{14}$ showed that use of an electrical impedance spectroscopic device (ZedScan I) increases detection of CIN2+ irrespective of hrHPV genotype. The observations in the previous study are in agreement with the findings of the present study.

\section{Conclusion}

The findings of the study conducted thus suggest that ZedScan has a useful role as an adjunct to Colposcopy in the detection of cervical neoplasia, particularly that of high-grade CINs. However, whether the additional detection will have an economic implication remains to be examined. One of the limitations of the present study was a lower biopsy-proven positivity rate and a relatively smaller sample size, further studies on larger sample size with economic impact as an additional variable for decision making are recommended.

\section{Source of Funding}

None.

\section{Conflict of Interest}

The authors declare that there is no conflict of interest.

\section{References}

1. Ferlay J, Bray F, Pisani P, Parkin DM. Globocan 2002: Cancer Incidence, Mortality and Prevalence Worldwide. IARC Cancer Base No. 5, version 2.0. Lyon, France: IARC Press; 2004.

2. Arbyn M, Castellsagué X, Sanjosé S, Bruni L, Saraiya M, Bray F, et al. Worldwide burden of cervical cancer in 2008. Ann Oncol.

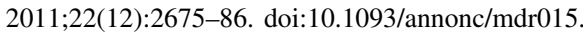

3. Yeole BB, Kumar AV, Kurkureet A, Sunny L. Population-based survival from cancers of breast, cervix and ovary in women in Mumbai. Asian Pac J Cancer Prev. 2004;5:308-15.

4. Goldie SJ, Gaffikin L, Goldhaber-Fiebert JD, Gordillo-Tobar A, Levin C, Mahe C. Alliance for Cervical Cancer Prevention Cost Working Group. Cost-effectiveness of cervical cancer screening in five developing countries. N Engl J Med. 2005;353:2158-68.

5. Harry TK, Felicia MS, Ngugen S. A needs assessment of barriers to cervical cancer screening in Vietnamese American Health Care Providers. Californian J Health Promot. 2006;4:146-56.

6. Nor HO, Matejka R. Challenges to cervical cancer screening in a developing country: The case of Malaysia. Asia Pac J Cancer Prev. 2009; 10:747-52.

7. Swan J, Breen N, Coates RJ, Rimer BK, Lee NC. Progress in cancer screening practices in the United States. Results from the 2000 National Health Interview Survey. Cancer. 2003;97:1528-40.

8. National Institute for Health and Care Excellence (NICE). The ZedScan as an adjunct to colposcopy in women with suspected cervical intra-epithelial neoplasia. Medtech Innovation Briefing. Published 12th February, 2015. Available from: https://www.nice.org.uk/advice/mib20/resources/the-zedscan-asan-adjunct-to-colposcopy-in-women-with-suspected-cervicalintraepithelial-neoplasia-63499038410437.

9. Sasieni P, Castanon A, Cuzick J. Effectiveness of cervical screening with age: population based case-control study of prospectively recorded data. BMJ. 2009;339:b2968. do1:10.1136/bmj.b2968.

10. Plummer M, Peto J. Time since first sexual intercourse and the risk of cervical cancer. Int J Cancer. 2012;130(11):2638-44. 
11. Sellors JW, Sankaranarayanan R. Colposcopy and treatment of cervical intraepithelial neoplasia: a beginners' manual. Lyon: IARC, World Health Organization; 2003.

12. Das L, Sarkar T, Maiti AK, Naskar S, Das S, Chatterjee J. Integrated cervical smear screening using liquid based cytology and

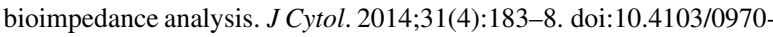

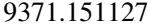

13. Balasubramani L, Brown BH, Healey J, Tidy JA. The detection of cervical intraepithelial neoplasia by electrical impedance spectroscopy: The effects of acetic acid and tissue homogeneity. Gynecol Oncol. 2009;115(2):267-71. doi:10.1016/1.ygyno.2009.08.010.

14. Macdonald MC, Brown BH, Lyon RE, Healey TJ, Palmer JE, Tidy JA. Influence of high risk HPV genotype on colposcopic performance: A large prospective study demonstrates improved detection of disease with ZedScan I , particularly in non-HPV 16 patients. Eur J Obstet Gynecol Reprod Biol. 2017;211:194-8. doi:10.1016/j.ejogrb.2017.02.020.
15. Abdul S, Brown BH, Milnes P, Tidy JA. The use of electrical impedance spectroscopy in the detection of cervical intraepithelial neoplasia. Int J Gynecol Cancer. 2006;16(5):1823-32. doi:10.1111/].1525-1438.2006.00651.X

\section{Author biography}

Shalini Vasudeva, Consultant

Ragini Thapa, Consultant (1) https://orcid.org/0000-0001-9985-2913

Cite this article: Vasudeva S, Thapa R. Colloseum to estimate the accuracy of detection of cervical intraepithelial neoplasia using electrical impedance spectroscopy with colposcopy- A one year study. Indian J Obstet Gynecol Res 2021;8(2):166-171. 